\title{
GPS TRACKER AND ALCOHOL DETECTOR WITH ENGINE LOCKING SYTEM USING GSM
}

\author{
Swetha.A, Pallavi.B, Pravallika.B, Madhuri.C, Jayasheela.T \\ Department of ECE \\ SSE College, Puttaparthi, Ap, India \\ Mr. Venkatesh. B (M Tech) \\ Asst. Professor, Dept. Of ECE \\ SSE College, Puttaparthi, Ap, India
}

\begin{abstract}
The motive of this project the alcohol is detected by the alcohol sensor MQ3 which is the senses in the car while incase drink alcohol, and the sensor send a signal to microcontroller which forward a particular signal to the GSM. The GSM send a message to a particular preregister mobile that the driver is drunken burger beeping and led is indicated red and then the engine will be locked. If any other person want to drive it send a particular message to the system will be unlocked but alcohol sensor continue working. In this way owner get the real location by receiving the exact position of the car. It will be copied to the google map and the location of that car and easily be accessed.
\end{abstract}

\section{INTRODUCTION}

These days, majority of road accidents are caused by drink driving. Drunken drivers are in an unstable condition and so, rash decision are made on highway which condition endangers the lives of road users, the driver inclusive. However, effective monitoring of drunk and drivers is the challenging to the policeman and the road safety officers. Many research officer's efforts have been directed to the design of efficient system that will monitor drunk driving. This project developed a prototype alcohol detection and engine locking system by using Arduino uno microcontroller interface with an alcohol sensor along with an lcd screen and a DC motor to demonstrate the concept. India had earned distinction in having more number of casualties due to road accidents around the world. Road safety is appearing as a big

social concern around the world especially in India. Drinking and driving is a serious issue which probably would emerge as one of the most significant problems in the near future. The system proposed by us focus at minimizing number of road accidents in the near future because of drunk driving. The system detects the alcohol level present in the air inside the vehicle. At low level it sends an SMS to the preregistered contacts while at high level it locks the engine immediately and at the same time sends SMS along with the location to three pre-selected contacts. Hence the system will reduce the number of road accidents and casualties due to drunk driving in future.

INDIA the world's second most populated country. Being a developing nation it faces many problems, which it tackles decently except road accidents. The mass/main reason for road accidents being drink and drive cases. Each year around 50,000 peoples die due to road accidents. The central nervous system is affected by alcohol. The ability to control steering is affected even at $0.05 \%$ BAC (Blood Alcohol Concentration). In case of public transport, the triggering of buzzer creates awareness among the passengers traveling in that vehicle. The GSM module sends the information of the position and alcohol content in the driver's body to the nearest police station by using GPS.

\section{EXISTING SYSTEM}

There are many works carried out on the drivers drowsiness detected. A large number of road accidents takes place due to the fatigue of drivers due to alcohol consumption. An embedded system with UNO and open CV is developed. Where the Alcoholic drivers are detected in real time using the drivers drowsiness and intoxication, since large number of road accidents takes place due to alcohol drinking. In the computer vision concept is used which has an alcohol gas sensors combined with the Raspberry pi micro-controller and embedded systems [1] AnARM based face recognition system is developed with open CV library using the ARM based micro-controller and USB camera to detect continuous image. The image captured is compared with the existing database and the output is sent to 


\section{International Journal of Engineering Applied Sciences and Technology, 2020 \\ Vol. 4, Issue 12, ISSN No. 2455-2143, Pages 615-618 \\ Published Online April 2020 in IJEAST (http://www.ijeast.com)}

the GPS and sent the information regarding the person to the authorises in charge using GSM. They used a vehicle based control in the school zone and controls the speed of the vehicle in brides, hospital areas and many other important areas [7]. Though there are many works carried out they concentre only on a specific feature and the accuracy level should be improved. The manual detection device that cops use, do analyze the breath and detect the alcohol consumption and penalize the defaulting drivers but then it becomes increasingly impossible for the traffic-cops to control, measure and monitor the vehicle movement given the size of modern-day traffic. It therefore becomes imperative for governmentauthorities to take advantage of the growingtechnology to prevent such accidents and possibly prevent drunken-driving. The theft of the vehicle is also a major concern today, so if any theft happing in the vehicle should be notified to the police or the vehicle owner.

\section{LITERATURE REVIEW}

In preview paper the authors have proposed many system to prevent the accidents due to drunken driving. Major drawback of this system is that they have used pic 16f877A microcontroller which is not as useful as 89 s52 microcontroller that we are using. also, they have used an old design system which is not useful and increases the overall cost of the system which makes it expensive and somewhat unaffordable to certain segments of society thereby limiting its scopes to be used. However, in the proposed project the alcohol is detected by the alcohol sensor MQ3 which is the senses in the car while incase drink alcohol, and the sensor send a signal to microcontroller which forward a particular signal to the GSM. The GSM send a message to a particular preregister mobile that the driver is drunkand durger beeping and led is indicated red and then the engine will be locked.

\section{PROPOSED SYSTEM}

The main components in this system is the alcohol sensor which is placed inside the vehicle. Sensors gives signal to the comparator. The comparator is connected to the micro controller. It gives signal to alert the buzzer. The components used in this system are represented in figure1 which consists of LCD, Buzzer, GSM Module, AT89S52, Power Supply, Jumper Wires, Micro controller, Alcohol Detector Module, Ultrasonic Distance Sensor. The proposed system of this project is shown in Fig 4.1.

\section{BLOCK DIAGRAM}

Alcohol sensor will detect the alcohol level from air, which is presented in the steering to detect the alcohol level in air breath out by driver. If level of alcohol is detected then it will be send message to microcontroller. Microcontroller compares the level of alcohol send by the sensor with normal level of alcohol. If the level of alcohol detected in the sensor is higher than normal level then microcontroller execute the code which would not allow the driver to start the car. If the alcohol level is become high while car in moving condition then the car will be slowed down like parking and send message to owner using GSM.

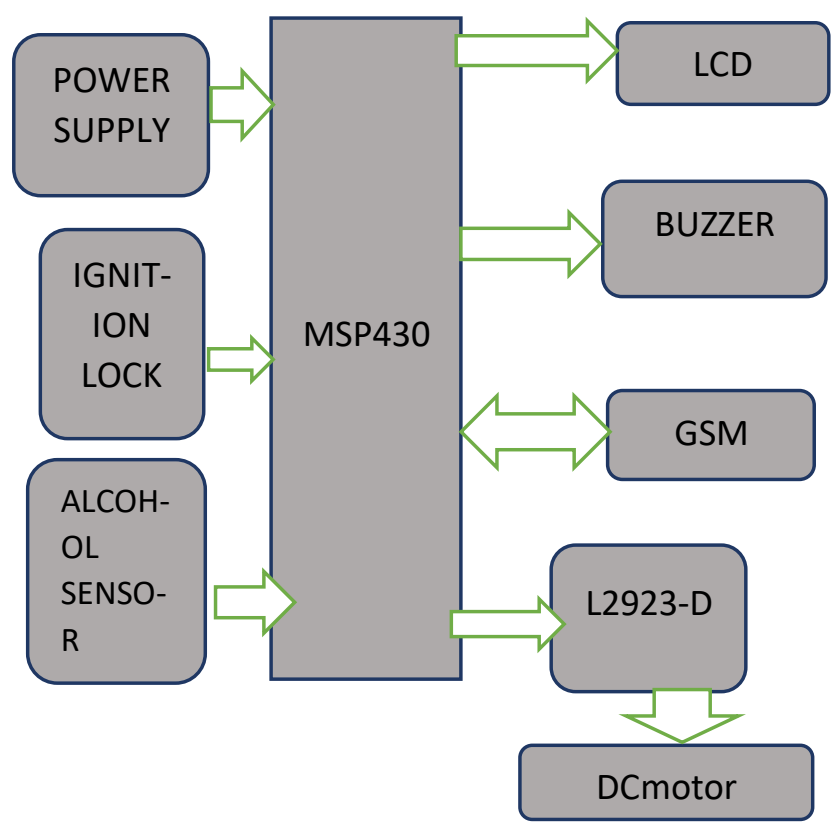

Fig 1: Block diagram

The project is actuated on switching on the vehicle with the help of the ignition key. This would actuate the working circuit and make the entire unit in a vigilant mode. Alcohol detection is performed in real-time by the alcohol sensor, the microcontroller, and Analog to digital converter circuit. Thus there is never a situation when the system is in a shadow or a sleep state. In the GPS based drunk and drive detection project, the system generates an alarm once the level of alcohol measured above a set threshold value. At the same time engine, locking is done with the help of deactivating Relay and DC motor. Also, it reads data from the GPS unit which gives the position of the vehicle to the microcontroller. Then the microcontroller sends SMS to the handheld mobile phone with the help of a GSM modem. The user can click on the link in the received SMS. The integration of the GPS tracker with Google Maps would ensure that the position of the offender is given out on the maps readily to ensure the easy location and possible further action. 


\section{International Journal of Engineering Applied Sciences and Technology, 2020 \\ Vol. 4, Issue 12, ISSN No. 2455-2143, Pages 615-618 \\ Published Online April 2020 in IJEAST (http://www.ijeast.com)}

Power supply: Power supply is a reference to a source of electrical power. A device or system that supplies electrical or other types of energy to an output load or group of loads is called a power supply unit or PSU. The term is most commonly applied to electrical energy supplies, less often to mechanical ones, and rarely to other This power supply section is required to convert AC signal to DC signal and also to reduce the amplitude of the signal. The available voltage signal from the mains is $230 \mathrm{~V} / 50 \mathrm{~Hz}$ which is an AC voltage, but the required is DC voltage (no frequency) with the amplitude of $+5 \mathrm{~V}$ and $+12 \mathrm{~V}$ for various applications

\section{ALCOHOL SENSOR}

This module is made using Alcohol Gas Sensor MQ3. It is a low cost semiconductor sensor which can detect the presence of alcohol gases at concentrations from $0.05 \mathrm{mg} / \mathrm{L}$ to $10 \mathrm{mg} / \mathrm{L}$. The sensitive material used for this sensor is $\mathrm{SnO} 2$, whose conductivity is lower in clean air. Its increases as the concentration of alcohol gases increases. It has high sensitivity to alcohol and has a good resistance to disturbances due to smoke, vapor and gasoline. This module provides both digital and analog outputs.MQ3 alcohol sensor module can be easily interfaced with Microcontrollers, Arduino Boards, Raspberry Pi etc. This alcohol sensor is suitable for detecting alcohol concentration on your breath, just like your common breathalyzer. It has a high sensitivity and fast response time. Sensor provides an analog resistive output based on alcohol concentration. The drive circuit is very simple, all it needs is one resistor. A simple interface could be a $0-3.3 \mathrm{~V}$ ADC.

Led (liquid crystal display): A liquid crystal display (LCD) is a thin, flat display device made up of any number of color or monochrome pixels arrayed infront of a light source or reflector. Eachpixel consists of a column of liquid crystal molecules suspended between two transparent electrodes, and two polarizing filters, the axes of polarity of which are perpendicular to each other.

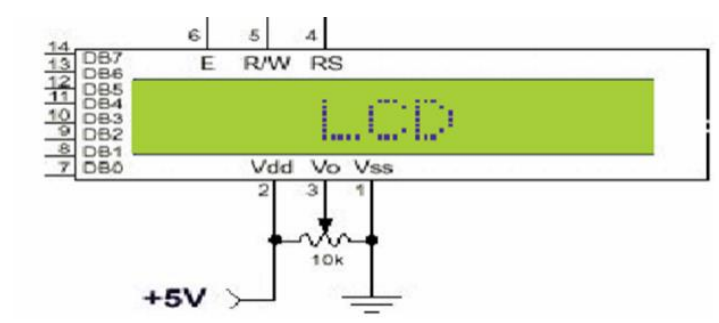

GSM (Global system for mobile communication): GSM (Global System for Mobile communications) is a cellular network, which means that mobile phones connect to it by searching for cells in the immediate vicinity. GSM networks operate in four different frequency ranges. Most GSM networks operate in the 900 $\mathrm{MHz}$ or $1800 \mathrm{MHz}$ bands. Some countries in the Americas use the $850 \mathrm{MHz}$ and $1900 \mathrm{MHz}$ bands because the 900 and $1800 \mathrm{MHz}$ frequency bands were already allocated. The rarer 400 and $450 \mathrm{MHz}$ frequency bands are assigned in some countries, where these frequencies were previously used for first-generation systems. GSM-900 uses 890-915 $\mathrm{MHz}$ to send information from the mobile station to the base station (uplink) and 935-960 MHz for the other direction (downlink), providing $124 \mathrm{RF}$ channels (channel numbers 1 to 124) spaced at 200 $\mathrm{kHz}$. Duplex spacing of $45 \mathrm{MHz}$ is used. In some countries the GSM-900 band has been extended to cover a larger frequency range. This 'extended GSM', E-GSM, uses 880-915 MHz (uplink) and 925-960 MHz (downlink), adding 50 channels (channel numbers 975 to 1023 and 0) to the original GSM-900 band. Time division multiplexing is used to allow eight full-rate or sixteen half-rate speech channels per radio frequency channel. There are eight radio timeslots (giving eight burst periods) grouped into what is called a TDMA frame. Half rate channels use alternate frames in the same timeslot. The channel data rate is $270.833 \mathrm{kbit} / \mathrm{s}$, and the frame duration is $4.615 \mathrm{~ms}$.

Buzzer: A buzzer or beeper is a signaling device, usually electronic, typically used in automobiles, household appliances such as a microwave oven, or game shows. It most commonly consists of a number of switches or sensors connected to a control unit that determines if and which button was pushed or a preset time has lapsed, and usually illuminates a light on the appropriate button or control panel, and sounds a warning in the form of a continuous or intermittent buzzing or beeping sound.

L2923D: The L293 and L293D are quadruple highcurrent half-H drivers. The L293 is designed to provide bidirectional drive currents of up to $1 \mathrm{~A}$ at voltages from $4.5 \mathrm{~V}$ to $36 \mathrm{~V}$. The L293D is designed to provide bidirectional drive currents of up to $600-\mathrm{mA}$ at voltages from $4.5 \mathrm{~V}$ to $36 \mathrm{~V}$. Both devices are designed to drive inductive loads such as relays, solenoids, $\mathrm{dc}$ and bipolar stepping motors, as well as other high-current/high-voltage loads in positive-supply applications. All inputs are TTL compatible. Each output is a complete totempole drive circuit, with a Darlington transistor sink and a pseudo- Darlington source

DC Motor: A DC motor is designed to run on DC electric power. Two examples of pure DC designs 


\section{International Journal of Engineering Applied Sciences and Technology, 2020 \\ Vol. 4, Issue 12, ISSN No. 2455-2143, Pages 615-618 \\ Published Online April 2020 in IJEAST (http://www.ijeast.com)}

are Michael Faraday's homopolar motor (which is uncommon), and the ball bear in motor, which is (so far) a novelty. By far the most common DC motor types are the brushed and brushless types, which use internal and external commutation respectively to create an oscillating $\mathrm{AC}$ current from the DC source so they are not purely DC machines in a strict sense.

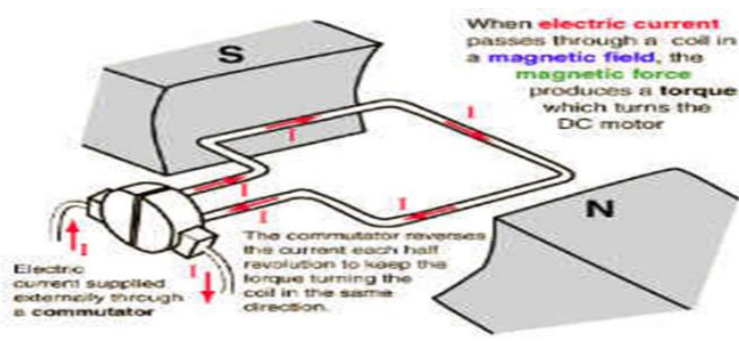

\section{CONCLUSION}

An effective solution is provided to develop the intelligent system for vehicles which will sense the various levels of alcohol present in the breath of the driver and would respond accordingly. The system adopted different principles as explained in this paper, by using hardware platform who's Core is Atmega8, Alcohol sensor mq3, GPS \& GSM module. The communication with preregistered phone numbers in this designed system is done via GSM, GPS and control of various parameters. The whole control system has the benefit of small volume and high reliability. Future scope of this system is to decrease accident numbers and providing useful details about the accidental vehicle, thereby reducing the rate of accidents taking place due to drunken driving. This system brings modernization to the existing technology in the vehicles and also maintains and improves the safety features, hence proving to be an effective development in the automobile industry.

\section{REFERENCE}

[1] Juha Hyyppa, et al "Map updating and change detection using vehicle-based laser scanning", Urban Remote Sensing Event, 22 May 2009.

[2] Tessa Tielert, Moritz Killat, Hannes Hartenstein, Raphael Luz, Stefan Hausberger, Thomas Benz, "The impact of traffic-light-tovehicle communication on fuel consumption and emissions", Internet of Things (IOT), 29 Nov.-1 Dec. 2010.

[3] Chi-Man Vong, et al "Framework of vehicle emission inspection and control through RFID and traffic lights", System Science and Engineering (ICSSE), 2011 International Conference, 8-10 June 2011.
[4] Yuxiang Sun, Nan Wu, et al"Development of driving support system for electric vehicle by using image processing technology", Control, Automation and Systems (ICCAS), 2012 12th International Conference, 17-21 Oct 2012.

[5] N. P. Jain, P. N. Jain, T. P. Agarkar, "An embedded, GSM based, multiparameter, realtime patient monitoring system and control — An implementation for ICU patients", Information and Communication Technologies (WICT), 2012 World Congress on 30 Oct.-2 Nov 2012

[6] Mehaseb Ahmed Mehaseb et al"WSN Application Traffic Characterization for Integration within the Internet of Things", Mobile Ad-hoc and Sensor Networks (MSN), 2013 IEEE Ninth International Conference, 11-13 Dec 2013.

[7] Chi-Man Vong, Pak-Kin Wong, Zi-Qian Ma, Ka-In Wong,"Application of RFID technology and the maximum spanning tree algorithm for solving vehicle emissions in cities on Internet of

Things", Internet of Things (WF-IoT), 2014 IEEE World Forum, 6-8 March 2014.

[8] Bill Montgomery, "IoT benefits beyond traffic and lighting energy optimization", IEEE Consumer Electronics Magazine, Volume: 4, Issue: 4, Oct. 2015

[9]M.SuryaDeekshith Gupta, Vamsikrishna Patchava, Virginia Menezes, "Healthcare Based On Iot Using Raspberry Pi", Green Computing And Internet Of Things (Icgciot), 2015 International Conference On 8-10 Oct 2015.

[10] Swati Rajesh Parekar, Manoj M. Dongre, “An intelligent system for monitoring and controlling of street light using GSM technology", Information Processing (ICIP), 2015 International Conference on 19 Dec 2015.

[11] Landu Jiang, Xi Chen, Wenbo He, "SafeCam: Analyzing intersectionrelated driver behaviors using multi-sensor smartphones", Pervasive Computing and Communications (PerCom), 2016 IEEE International Conference, 14-19 March 2016. [12] Tumisang Liphoto, Muthoni Masinde, "Ubiquitous traffic management with fuzzy logic - Case study of Maseru, Lesotho",IST-Africa Week Conference, 11-13 May 2016

[13]http://pibphoto.nic.in/documents/rlink/2016/jun /p20166905.pdf

[14]R. Sanchez-Iborra, J.F. Ingles-Romero, G.Domenech-Asensi,J.L. Moreno-Cegarra, MariaDolores Cano, "Proactive Intelligent Systemfor Optimizing Traffic Signaling", Dependable,AutonomicandSecure Computing, 1 2016 IEEE 14th Intl C, 8-12 Aug 2016. 